\title{
ASESORÍA GENÉTICA SOBRE CÁNCER EN EL PERÚ
}

\author{
Javier E. Manrique ${ }^{1, a}$, Yasser Sullcahuamán-Allende ${ }^{2, b}$, Abel Limache-García ${ }^{1, c}$ \\ RESUMEN \\ El cáncer es una enfermedad genética producto de alteraciones en la secuencia o expresión del ADN. Estas \\ alteraciones, según su origen, nos permiten clasificar el cáncer como esporádico y hereditario o familiar. En \\ base a los registros de cáncer, en el Perú se espera que del 5 al 30\% de todos los pacientes con cáncer, que \\ equivale aproximadamente entre 2000 a 12000 personas, presentarían cáncer del tipo familiar o hereditario, lo que \\ representaría un similar número de familias con un riesgo mayor de desarrollar cáncer que el de la población en \\ general. El propósito de la asesoría genética es identificar cánceres hereditarios en una familia con el fin de prevenir \\ la enfermedad y la muerte por este mal. Es una estrategia que nos puede permitir detectar y diagnosticar con \\ antelación estos cánceres. Es por este motivo que en el Instituto Nacional de Enfermedades Neoplásicas del Perú \\ se realizan consultas de diagnóstico y asesoría genética desde hace cinco años, constituyéndose en un elemento \\ importante para la lucha contra el cáncer, sin embargo, para lograr un mayor impacto en la salud requiere ampliar \\ y fortalecer el proceso de capacitación en genética y asesoría genética a profesionales de la salud, sobre todo a \\ médicos y enfermeras.
}

Palabras clave: Asesoramiento genético; Neoplasias; Prevención; Detección; Diagnóstico; Biología molecular (fuente: DeCS BIREME).

\section{GENETIC COUNSELING ABOUT CANCER IN PERU}

\begin{abstract}
Cancer is a genetic disease caused by changes in the DNA sequence or expression. Based on the origin of these changes, cancer can be classified as sporadic, and hereditary or familial. Based on the cancer records in Peru, it is expected that 5 to $30 \%$ of all patients with cancer, i.e. about 2,000 to 12,000 people, have hereditary cancer, meaning that a similar number of families have a higher risk of developing cancer compared to the general population. Therefore, the purpose of genetic counseling is to identify hereditary cancers running in the family in order to prevent diseases and deaths caused by this condition. It is a strategy that allows us to detect and diagnose these types of cancer very early. For this reason, the National Institute of Neoplastic Diseases of Peru has been providing genetic diagnosis and counseling services for five years, and represents an important element in the fight against cancer. However, in order to have a greater impact on health, it is necessary to expand and strengthen the training process in genetics and genetic counseling to health care professionals, particularly to physicians and nurses.
\end{abstract}

Key words: Genetic counseling; Neoplasms; Prevention; Detection; Diagnosis; Molecular biology (source: MeSH NLM).

\section{INTRODUCCIÓN}

El cáncer es un problema de salud pública a nivel mundial, los registros demuestran que las tasas de incidencia y mortalidad se están incrementando; según informes de Globocan 2008 se esperaba 12661281 pacientes nuevos con cáncer, así como 7564800 decesos por esta enfermedad, correspondiendo un porcentaje importante a los países en vías de desarrollo $(56,1 \%)^{(1)}$, según esta misma fuente, en el Perú se esperaba 39305 casos nuevos y 24828 muertes por cáncer.
Actualmente, se sabe que el cáncer es una enfermedad genética producto de alteraciones en la secuencia o expresión del ADN. Estas alteraciones, según su origen, nos permiten clasificarlas como:

a) Cáncer esporádico, el cual se presenta entre el 70 a $90 \%$ de los casos, generalmente no tiene familiares afectados y se presentan pasados los 40-50 años.

b) Cáncer hereditario o familiar, el cual se presenta entre el 5 a $30 \%$ de los casos, el diagnóstico de cáncer familiar se sustenta en la presencia de

\footnotetext{
Dirección de Promoción de la Salud, Prevención y Control Nacional del Cáncer, Instituto Nacional de Enfermedades Neoplásicas. Lima, Perú.

2 Unidad de Genética y Biología Molecular, Instituto Nacional de Enfermedades Neoplásicas. Lima, Perú.

Cirujano oncólogo, ${ }^{\mathrm{b}}$ médico genetista; ${ }^{\mathrm{c}}$ enfermero

Recibido: 28-01-13 Aprobado: 20-02-13
}

Citar como: Manrique JE, Sullcahuamán-Allende Y, Limache-García A. Asesoría genética sobre cáncer en el Perú. Rev Peru Med Exp Salud Publica. 2013;30(1):118-23. 
familiares afectados de cáncer, generalmente dos o más con el mismo tipo de cáncer o diferentes pero en personas menores de 50 años, muchas veces en estas familias no se puede identificar el gen mutado debido a que este aún no ha sido descubierto o a su baja penetrancia ${ }^{(2)}$. El diagnóstico de cáncer hereditario se basa en características clínicas específicas, un patrón de herencia reconocible o la evidencia de una mutación conocida en un gen de predisposición genética, con estas características se han descrito más de doscientos tipos de cáncer hereditario, que serían responsables de aproximadamente el 5 a $10 \%$ de todos los casos.

En base a las cifras estimadas de casos nuevos por año, en el Perú se espera que aproximadamente entre 2000 a 12000 personas presenten cáncer de tipo familiar o hereditario, lo que representaría una similar cantidad de familias con un riesgo mayor de desarrollar cáncer que el de la población en general. Este riesgo empíricamente se calcula como de un 50 a $98 \%$ de presentar cáncer en los integrantes de las familias antes de cumplir los cuarenta años, incluso como el caso del retinoblastoma, este podría presentarse antes de nacer o en los primeros dos años, el cáncer de colon se presentaría a partir de los 12 años, en el caso de cáncer de mama entre los 20 y 40 años, estas circunstancias de enfermedad implican un cambio en las políticas y estrategias de diagnóstico del cáncer, puesto que se requiere una atención personalizada por lo cual la asesoría genética es una respuesta a esta necesidad.

El cáncer hereditario se puede diagnosticar mediante la elaboración de una óptima historia clínica (antecedentes familiares, personales, síntomas, examen físico, signos, número de tumores, etc.) o mediante el estudio familiar que, básicamente, se centra en el estudio del árbol genealógico y los patrones de herencia que se puedan identificar, los cuales son de carácter autosómico dominante. Otra forma de llegar al diagnóstico de cáncer hereditario es mediante el estudio de genes de predisposición y la evidencia de mutaciones, este tipo de estudios moleculares se solicita una vez que se realiza la evaluación clínica, que nos permite tener una alta sospecha y plantear de manera razonable cual es el posible gen responsable de la enfermedad.

A partir de 1980 se empiezan a identificar genes de predisposición para cáncer mediante secuenciamiento y análisis de ligamiento, que permitía el cálculo $L O D$ score (Logarithm-of-odds), cuando este era superior a tres significaba que existía una alta probabilidad de encontrar el gen responsable de esta susceptibilidad; a partir del 2010, con el uso de secuenciadores de última generación y el desarrollo de las matemáticas y bioinformática, se puede hacer el secuenciamiento completo del genoma humano en un tiempo de seis semanas y es posible identificar genes de alta y media penetrancia de predisposición para el desarrollo de cáncer.

En general, los pacientes procedentes de familias que manifiesten alguna de las siguientes características deberían ser evaluados para la presencia de un cáncer hereditario ${ }^{(3)}$ :

- Dos o más familiares diagnosticados de cáncer.

- Un miembro de la familia diagnosticado de cáncer antes de los 50 años de edad.

- Varios miembros de la familia afectados por el mismo tipo de cáncer.

- Un familiar afectado por más de un tipo de cáncer.

- Uno o más miembros de la familia afectados de un cáncer raro.

Sin embargo, no siempre un síndrome tumoral hereditario se puede reconocer fácilmente puesto que existen fenómenos como la penetrancia incompleta, la expresividad variable o el imprinting genético, o patrones de herencia irreconocibles, los cuales pueden ocultar su presencia. Por otra parte, la elevada incidencia de casos de cáncer en una misma familia no implica necesariamente una base genética, sino que pueden existir factores ambientales que la expliquen ${ }^{(4)}$. Como se sabe, el cáncer es una enfermedad frecuente y es habitual encontrar casos de cáncer en la mayoría de las familias, más del $90 \%$ de los tumores son esporádicos, es decir, los factores ambientales van a tener un rol importante en su aparición, estos factores ambientales, pueden ser los que ocasionen daño o alteración en la constitución del ADN y funcionabilidad celular, como es el caso de factores de riesgo muy importante y comprobadamente generadores de cáncer, como el consumo de cigarrillos y sus más de 60 sustancias cancerígenas (IARC), agentes infecciosos como el virus de papiloma humano, el Helicobacter pilory, la dieta no saludable, el sedentarismo, la obesidad, el consumo prolongado de hormonas, entre otros.

\section{CARACTERÍSTICAS DEL CÁNCER HEREDITARIO}

Las primeras evidencias sobre una susceptibilidad genética para desarrollar cáncer surgieron a partir de estudios epidemiológicos realizados en los años cuarenta, los cuales mostraban un riesgo incrementado a padecer cáncer en los familiares de pacientes con cáncer ${ }^{(5)}$.

En la actualidad, se conoce alrededor de 200 síndromes de susceptibilidad hereditaria que incrementan el riesgo 
de padecer cáncer, heredándose la mayor parte de ellos de un modo autosómico dominante ${ }^{(5)}$. Según el modelo de herencia mendeliano existe un $50 \%$ de probabilidades de que se herede un alelo alterado, que independiente de la penetrancia o expresividad genética, se incrementa el riesgo de desarrollar cáncer. En la herencia dominante, la existencia de un solo alelo mutado sería suficiente para producir la enfermedad y, por tanto, todos los portadores potencialmente podrían desarrollar enfermedad. Sin embargo, hoy en día se sabe también que la mayor parte de la susceptibilidad al cáncer sigue un modelo poligénico, siendo posible en estos casos tanto una herencia dominante como recesiva ${ }^{(4)}$.

Es importante reconocer y describir algunas características del cáncer hereditario para su identificación y diferenciación del cáncer esporádico, las principales son:

Alta incidencia de cáncer en la familia. Suele ser la señal de alarma más común y la principal causa de consulta. En estas familias se observa una elevada agregación de cánceres que va más allá de la mera concurrencia debida al azar.

Ocurrencia del mismo tipo de cáncer. Generalmente se observa el mismo tipo de cáncer, como el que afecta la mama, colon, estómago entre otros y aparece en generaciones sucesivas de acuerdo a los modelos mendelianos de herencia. A veces puede observarse una anormalmente elevada frecuencia de tumores en una única generación en la familia, cuya explicación podría estar en la existencia de una posible mutación en un gen autosómico recesivo.

Aparición del cáncer a edad temprana. El cáncer hereditario suele aparecer antes de la edad en la que es frecuente la aparición de la forma esporádica de ese mismo tipo de cáncer. Por ejemplo, la edad media de aparición del cáncer colorrectal esporádico es de 60 años, mientras que la edad media de aparición del cáncer colorrectal asociado al síndrome de Lynch es de 44 años, es decir, 20 años más joven ${ }^{(6)}$. En relación al cáncer de mama, la aparición se realiza a la edad promedio de 50 años, mientras que los cánceres de mama asociados a mutaciones en los genes BRCA1 y BRCA2 tienen una edad promedio de aparición más temprana (alrededor de 40 años).

Bilateralidad en el caso de afectación de órganos pares. Es frecuente observar bilateralidad en los casos hereditarios de retinoblastoma, de cáncer de mama y en los cánceres renales.

Multifocalidad. No es raro observar que los tumores hereditarios se inician de manera independiente en varios focos repartidos en el mismo órgano donde se inicia, en vez de aparecer en un único foco.

Aparición de varios cánceres en el mismo individuo. En estos casos es importante determinar si se trata de neoplasias primarias o de recurrencias de un tumor anterior. Solo cuando se trata de varias neoplasias primarias es más probable que exista un síndrome de cáncer hereditario. Es importante mencionar que, en ocasiones, las segundas neoplasias pueden guardar relación con el tratamiento de neoplasias anteriores.

Cuando en un paciente, o en una familia, se observa alguna o varias de estas características, es necesario realizar una consulta genética para llegar al diagnóstico, determinar los posibles genes responsables, establecer el mejor estudio molecular y, en este contexto, recibir la asesoría genética adecuada.

\section{ASESORÍA GENÉTICA}

La asesoría genética está compuesta por dos partes fundamentales: la consulta y el laboratorio. La consulta es el espacio donde los especialistas que reciben al paciente diseñan el estudio genético; allí se recopila la información, se decide qué tipo de investigación requiere el entorno familiar que se estudia y, llegado el caso, se indica la prueba genética correspondiente. Además, será el especialista en asesoría genética el encargado de comunicar al paciente los resultados del estudio, una de las partes más delicadas del proceso. Es también el especialista quien brinda las primeras orientaciones a seguir en caso de que la asesoría genética sea positiva y el paciente tenga riesgo de padecer un cáncer de tipo hereditario. En esta última parte deberían incorporarse también a otros profesionales como los psicólogos quienes pueden vigilar el impacto que la información resultante del proceso puede causar en el paciente y en su familia.

El otro elemento fundamental es el laboratorio especializado en genética, donde los especialistas analizan el ADN de los pacientes y buscan en él, anomalías que permitan valorar la posibilidad de que puedan desarrollar cáncer. Su objetivo, además, es determinar si esas anomalías son hereditarias o no.

Aparentemente, el propósito de la asesoría genética puede ser sencillo: buscar cánceres hereditarios en una familia; sin embargo, no es así; la asesoría genética busca identificar a las familias en riesgo a desarrollar cáncer y asesorarlas en la toma de decisiones para detectar y diagnosticar con antelación esos cánceres, la asesoría genética identifica elementos que les permitan intuir la 
presencia de alteraciones genéticas que predispongan a los pacientes a sufrir determinados tipos de cáncer ${ }^{(7)}$. Por lo que puede entenderse a la asesoría genética como una herramienta eficaz de diagnóstico precoz.

Conforme se puede observar, la asesoría genética permite revisar la historia médica y familiar, explicar cómo las condiciones genéticas pueden pasar de una generación a otra, lo cual ayuda a representar a la persona y familia que están en riesgo de enfermedad, además brinda información sobre las condiciones genéticas, información sobre las opciones de detección y lo que es mejor para el paciente y su familia ${ }^{(8)}$; el objetivo de la asesoría genética es ayudar a la población a aprender sobre las causas de las condiciones genéticas y cómo les podría afectar. Por ejemplo:

a) Cáncer de mama/ovario hereditario. Los estudios realizados en las familias con alto riesgo permitieron identificar, en el 30 a $40 \%$, dos genes de alta penetrancia BRCA1 y BRCA2, ambos incrementan la probabilidad de desarrollar cáncer de mama y ovario hasta en un $80 \%$. Otros genes descritos con menor frecuencia son ATM, BRIP1, PALB2 y p53 que incrementan el riesgo para cáncer de mama y también de otros tejidos. La mejor medida de control es la prevención y el diagnóstico temprano, los métodos de control deben iniciarse en promedio entre los 20 a 30 años de edad, se recomiendan ecografías de mama, ovarios, mamografía y resonancia magnética una vez al año. Las familias con mayor riesgo de desarrollar este cáncer están descritas en la Tabla 1.

b) Cáncer de colon hereditario. Clínicamente se presenta como: i) Cáncer hereditario de colon no polipósico (HNPCC), se caracteriza por la presencia de cáncer de colon generalmente antes de los 40 años, también incrementa el riesgo de cáncer gástrico y en mujeres el riesgo de cáncer de endometrio y mama. Molecularmente presentan inestabilidad de microsatélites asociada a mutaciones en genes reparadores. ii) Cáncer hereditario de colon polipósico, se relaciona a mutaciones del gen APC, presentan más de 10 a 1000 pólipos antes de los 40 años; generalmente el riesgo de presentar cáncer de colon es de $98 \%$ antes de los 50 años, en los portadores

Tabla 1. Características familiares de riesgo para el desarrollo de cáncer hereditario de mama/ovario y colon.

\section{Cáncer de mama/ovario hereditario}

\section{Familias de riesgo alto}

- Un familiar con cáncer de mama a edad menor de 40 años.

- Cáncer de mama y cáncer de ovario en la misma paciente, a cualquier edad.

- Dos o más casos de cáncer de mama, uno de ellos diagnosticado a edad menor de 50 años, o bilateral.

- Un caso de cáncer de mama diagnosticado a edad menor de 50 años o bilateral, y un cáncer de ovario en un familiar de primer o segundo grado.

- Tres casos de cánceres de mama u ovario (al menos uno de ovario), en familiares de primer o segundo grado.

- Dos casos de cáncer de ovario en familiares de primer o segundo grado.

- Un caso de cáncer de mama en varón, y otro caso de cáncer de mama (varón o mujer) u ovario en un familiar de primer o segundo grado.

\section{Familias de riesgo moderado}

- Dos cánceres de mama en parientes de primer grado, diagnosticados entre los 51 y 60 años.

- Un cáncer de mama en un familiar de primer grado y otro en un familiar de segundo grado, si la suma de las edades al diagnóstico es $\leq 118$ años $^{4}$.
Cáncer de colon hereditario

\section{Familias de riesgo alto}

Criterios de Ámsterdam II.- Deben de cumplirse todos los siguientes criterios:

- Al menos tres familiares con cáncer asociado al cáncer colorrectal hereditario no polipósico o cáncer colorrectal, de endometrio, de estómago, de ovario, de uréter/pelvis renal, de cerebro, del intestino delgado, del conducto hepatobiliar y cutáneo tumores sebáceos, confirmados mediante estudio histopatológico.

- Un caso debe ser pariente en primer grado de los otros dos.

- Al menos dos generaciones sucesivas afectadas.

- Al menos un caso debe ser diagnosticado antes de los 50 años.

- La poliposis adenomatosa familiar debe estar excluida como posibilidad diagnóstica.

Criterios de Bethesda.-

- Cáncer colorrectal diagnosticado antes de los 50 años de edad.

- Presencia de tumores colorrectales sincrónicos, metacrónicos, $\mathrm{u}$ otros tumores asociados a HNPCC, independientemente de la edad.

- Cáncer colorrectal con una histología asociada a la inestabilidad de microsatélites diagnosticado en pacientes con edad $<60$ años.

- Al menos un pariente de primer grado con cáncer colorrectal o un tumor asociado con HNPCC y diagnosticados antes de los 50 años.

- Al menos dos parientes de primer o de segundo grado con cáncer colorrectal o un tumor asociado con HNPCC diagnosticado a cualquier edad. 
de otras mutaciones como MYH, SMAD4, BMPR1A, STK11 la probabilidad de presentar cáncer es menor y se presentan a mayor edad, se recomienda los estudios de colonoscopia a partir de los 20 años; sin embargo, se han descrito casos presentados a menor edad y se debería evaluar en cada caso para determinar a qué edad es la más adecuada para iniciar las evaluaciones del tracto gastrointestinal.

c) Cáncer de próstata. Recientes estudios realizados en familias con cáncer de próstata han establecido relación entre mutaciones en el gen $M S M B{ }^{(9)}$ y cáncer de próstata hereditario; sin embargo, no se ha podido demostrar esta relación en todas las familias y aún queda mucho por investigar. En otras familias, sobre todo con antecedentes de cáncer de mama, se ha determinado que están relacionados genes reparadores como BRCA2 que incrementa el riesgo en 20 veces más que la población en general.

d) Cáncer gástrico difuso hereditario. Presenta mutaciones del gen $\mathrm{CDH} 1$, las familias afectadas deben iniciar controles de gastroscopia y biopsia una vez al año, la edad de inicio de controles es antes de los 20 años. Se plantea también la cirugía profiláctica; sin embargo, dado que esta mutación la tiene el portador desde su nacimiento el manejo de gastrectomía profiláctica deberá ser evaluado en cuanto a la temporalidad a realizarse el procedimiento $y$, en aquellos casos que no opten por esta opción, se procederá a realizar seguimiento endoscópico.

e) Otros síndromes de predisposición genética. Se han descrito más de 200 síndromes, entre los que han sido atendidos con más frecuencia en el consultorio de genética esta la neurofibromatosis tipo 1(NF1), Von Hippel Lindau (VHL), schwanomatosis, etc. Generalmente estos síndromes se caracterizan por la presencia de manifestaciones clínicas no oncológicas, como el caso de las manchas café con leche en NF1, quistes renales, pancreáticos y hemangioblastomas para VHL, etc ${ }^{(10)}$. Este grupo de pacientes requieren la atención de un equipo de especialistas que nos permitan un correcto diagnóstico genético y una asesoría adecuada.

Los avances en el conocimiento de las bases genéticas de las enfermedades permiten llevar a cabo una prevención encaminada a evitarlas, o al menos minimizar sus consecuencias. La identificación de individuos y familias con un riesgo incrementado de desarrollar cáncer permite, además de una valoración individualizada del riesgo de desarrollar la enfermedad, recomendar estrategias de prevención y diagnóstico precoz adecuadas en cada caso ${ }^{(10)}$. Es importante tener en cuenta también la ventaja que proporciona el identificar un caso hereditario desde el punto de vista terapéutico, ya que el diagnóstico precoz de la enfermedad no solo puede mejorar su tratamiento sino que, en algunos casos, es fundamental para evitar su diseminación a distancia (metástasis).

Conforme se mencionó, la incidencia de casos de cáncer en una misma familia no implica necesariamente una base genética, sino que es posible que además existan factores ambientales y de estilos de vida que influyan en su presentación.

En el INEN, desde hace cinco años se realizan consultas de diagnóstico y asesoría genética, habiéndose atendido en el 2012 a más de 120, y a lo largo de los cinco años se atendieron aproximadamente un total de 1000 familias, las cuales representan 10000 a 15000 personas, quienes recibieron asesoría genética por el riesgo personal y familiar de desarrollar cáncer, siendo los síndromes más frecuentes de cáncer hereditario: el síndrome de cáncer de mama ovario; el colorrectal no polipósico; el cáncer gástrico; el cáncer hereditario polipósico, y otros síndromes genéticos de predisposición.

En ese sentido, la asesoría genética es un instrumento eficaz para identificar personas y familias asintomáticas o con riesgo de desarrollar cáncer; sin embargo, para lograr un mayor impacto en la lucha contra el cáncer a nivel nacional, se requiere de un proceso de capacitación a profesionales de la salud en genética y asesoría genética, para asumir las medidas preventivas y de detección temprana a través de la asesoría genética y del diagnóstico genético.

\section{CONCLUSIONES}

El cáncer es una enfermedad genética producto de alteraciones en la secuencia o expresión del ADN, estas alteraciones, según su origen, nos permiten clasificar el cáncer como cáncer esporádico y cáncer hereditario o familiar. En base a los registros de cáncer, en el Perú se espera que entre 1965 a 11791 personas presenten cáncer familiar.

El control del cáncer debería de tomar esta clasificación con el fin de poner en práctica medidas específicas para su control dada la condición genética de cada persona, sabiendo que quien tiene una mutación tiene un riesgo del 80 a $100 \%$ de desarrollar cáncer en comparación a quien no tiene mutaciones, cuyo riesgo es de $10 \%$.

Tomando en cuenta la experiencia que se tiene en el consultorio de oncogenética del INEN deberíamos de replicarlo como una estrategia importante para el control 
del cáncer en diferentes establecimientos de salud para lograr la identificación de personas y familias con mayor riesgo de desarrollar cáncer.

Contribuciones de autoría: todos los autores han participado en la concepción y diseño del artículo, recolección de la información, interpretación de los mismos y en la redacción del artículo final.

Fuentes de financiamiento: autofinanciado.

Conflictos de interés: los autores declaran no tener ningún conflicto de interés.

\section{REFERENCIAS BIBLIOGRÁFICAS}

1. International Agency for Research on Cancer. GLOBOCAN 2008 [Internet]. Lyon: OMS; c2010 [citado el 14 de enero de 2013]. Disponible en: http://globocan.iarc.fr/

2. Foulkes WD. Inherited susceptibility to common cancers. N Engl J Med. 2008;359(20):2143-53.

3. Sifri R, Gangadharappa $S$, Acheson LS. Identifying and testing for hereditary susceptibility to common cancers. CA Cancer J Clin. 2004;54(6):309-26.

4. Bandrés Moya F, Urioste Azcorra M, et al. Planteamientos básicos del cáncer hereditario principales síndromes. Edita Comunicación Gráfica, S.l. Madrid, 2011
5. Nagy R, Sweet K, Eng C. Highly penetrant hereditary cancer syndromes. Oncogene. 2004;23(38):6445-70.

6. Casimiro C. Factores etiopatogénicos en el cáncer colorrectal. Aspectos nutricionales y de estilo de vida (segunda de dos partes). Nutr Hosp. 2002; 17(3):128-38.

7. Fundación para la Investigación del Cáncer. Consejo genético. Guía para prevenir el cáncer hereditario. Salamanca: Fundación para la Investigación del Cáncer; 2009.

8. National Society of Genetic Counselors; Genetic Alliance. Making Sense of Your Genes. A Guide to Genetic counseling. Washington (DC): Genetic Alliance; 2008.
9. Eeles RA, Kote-Jarai Z, Giles GG, Olama AA, Guy M, Jugurnauth SK, et al. Multiple newly identified loci associated with prostate cancer susceptibility. Nat Genet. 2008; 40(3):316-21.

10. Sociedad Española de Oncología Médica (SEOM). Cáncer hereditario. Madrid: Dispublic, S.L.; 2006.

Correspondencia: Javier Manrique Hinojosa Dirección: Av. Caminos del Inca 2830-506. Lima 32, Perú.

Teléfono: (511) 998709523

Correo electrónico:

javiermanriquehinojosa@gmail.com

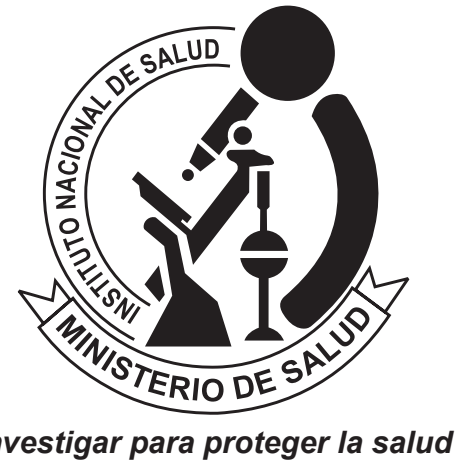

REVISTA PERUANA DE MEDICINA EXPERIMENTAL Y SALUD PÚBLICA CUMPLIENDO SUS METAS Y PROYECTÁNDOSE AL FUTURO

\section{Visite los contenidos de la revista en: www.ins.gob.pe/rpmesp}

